\title{
Von Pflanzen inspirierte Antireflexfolie
}

\author{
Eine Folie mit dem Namen „Phytonics" mit Mikro- und Nanostrukturen nach dem Vorbild von \\ Rosenblütenblättern entspiegelt Oberflächen aller Art, macht Solarmodule bis zu zehn Prozent \\ effizienter und verleiht vielen Gegenständen ein edles samtiges Erscheinungsbild.
}

In vielen Millionen Jahren Evolution haben sich Pflanzen optimal auf die Interaktion mit Licht eingestellt. Bei Blütenpflanzen hängt der Bestäubungserfolg wesentlich vom Farbeindruck ab. Dies zeigt sich besonders deutlich bei Rosen, deren Blütenblätter eine matte und zugleich satte Farbe aufweisen. Unter dem Rasterelektronenmikroskop offenbart die Rose ihr Geheimnis: Das äußere Abschlussgewebe ihrer Blütenblätter, die Epidermis, besteht aus dicht gedrängten Mikrostrukturen, zusätzlich gerippt durch Nanostrukturen. Mit den winzigen Strukturen gelingt es der Rose, alles einfallende Licht in die Zellen einzukoppeln - nur das farbige Licht tritt wieder aus.

\section{Vorteile von hochglänzenden und matten Oberflächen vereint}

Von diesem Prinzip hat sich Phytonics, ein Spin-off aus dem Karlsruher Institut für Technologie (KIT), zu einer Antireflexfolie für verschiedenste Oberflächen inspirieren lassen. „Unsere Folie ermöglicht es, die Vorteile von hochglänzenden und matten Oberflächen zu vereinen, nämlich inten-
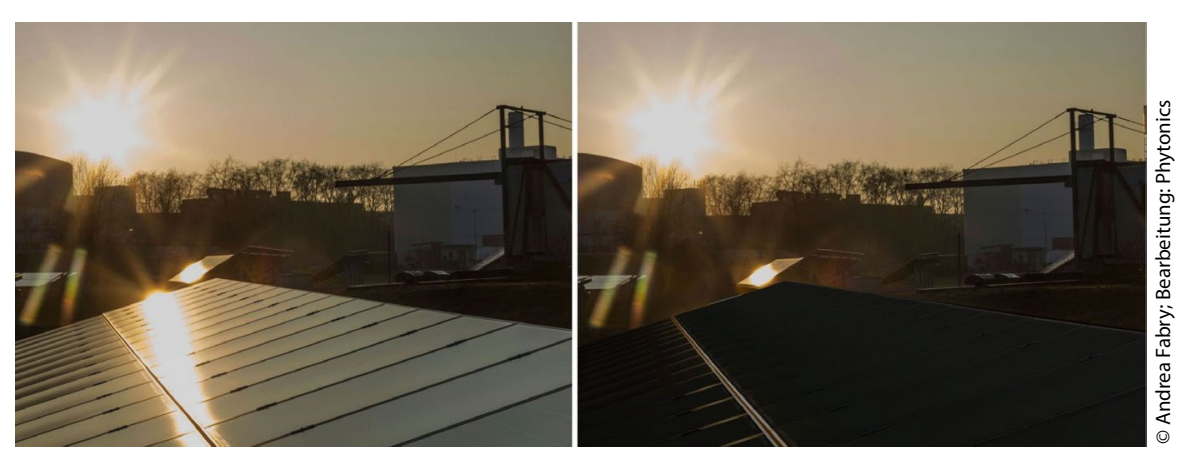

Solarmodule ohne (links) und mit (rechts; visualisiert) Phytonics Folie. Die Folie unterdrückt die Reflexion für alle Wellenlängen und Einfallswinkel des Lichts fast komplett. sive Farben ohne störende Reflexionen zu erreichen“, erklärt Dr. Ruben Hünig, Mitgründer von Phytonics. Bei der digitalen Hannover Messe 2021 stellte das Start-up seine Antireflexfolie am virtuellen Stand „Future Hub“ des KIT erstmals vor.

Forschende am KIT gründeten Phytonics aus der Motivation heraus, den nachhaltigen Umbau des Energiesystems mit effizienter Photovoltaik voranzubringen und dazu Solarzellen mit breitem Absorptionsspektrum und hoher Einfallswinkeltoleranz zu entwickeln. Dabei lassen sie sich von Pflanzen inspirieren. Dies soll sich im Namen widerspiegeln: Im Wort Phytonics verschmelzen Phyto und Photonics. Ab 2021 erhält das Hightech-Start-up eine Förderung im Programm EXIST-Forschungstransfer des Bundesministeriums für Wirtschaft und Energie und des Europäischen Sozialfonds (ESF).

\section{Ertrag von Solarmodulen bis zu zehn Prozent gesteigert}

Die Phytonics Antireflexfolie ist das Ergebnis von mehr als sieben Jahren For- schungs- und Entwicklungsarbeit. Mit ihrer kombinierten Mikro- und Nanostrukturierung bildet sie die Epidermis von Rosenblütenblättern auf großer Fläche nach. Sie unterdrückt die Reflexion für alle Wellenlängen und Einfallswinkel des Lichts fast komplett. Damit ist sie herkömmlichen Antireflexbeschichtungen weit überlegen. Die Phytonics Folie bringt bei Solarmodulen eine Ertragssteigerung bis zu $10 \%$. Doch auch Poster, Anzeigetafeln, Verkehrszeichen, Möbelstücke, Verpackungen, Fassaden und viele weitere Anwendungen profitieren von Phytonics. Die Folie entspiegelt Oberflächen aller Art und verleiht ihnen ein edles samtiges Erscheinungsbild.

Da die Phytonics Folie mechanisch flexibel ist, eignet sie sich auch für gekrümmte Oberflächen. Sie wirkt schmutzabweisend und ist hochbeständig gegenüber Umwelteinflüssen, wie UV-Licht, Nässe und Temperaturschwankungen. Hergestellt wird sie mit einem kostengünstigen Rolle-zu-Rolle-Druckverfahren. Aufbringen lässt sie sich mit Standard-Laminationsverfahren auf Materialien aller Art. Produktdesignern eröffnet die von Pflanzen inspirierte Folie damit ganz neue Gestaltungsfreiheiten. //

\section{Kontakt}

Karlsruher Institut für Technologie KIT Karlsruhe info@kit.edu www.kit.edu 